\title{
Knowledge and Practice of Daily Exercises for the Prevention and Control of Heart Diseases among Nurses in Anambra State
}

\author{
${ }^{1}$ Okeke, Joy E., ${ }^{1}$ Ilo, Clementine I., ${ }^{1}$ Egboka, Oluchukwu L., \\ ${ }^{1}$ Okafor, Christiana N., ${ }^{1}$ Nwankwo, Clementina U., ${ }^{1}$ Anieche John E. \\ $\&^{2}$ Umunna, Joseph O. \\ ${ }^{1}$ Department of Nursing Science Nnamdi Azikiwe University Nnewi Anambra State. Nigeria \\ ${ }^{2}$ Department of Medical Rehabilitation \& Physiotherapy Nnamdi Azikiwe University Nnewi \\ Anambra State. Nigeria
}

\begin{abstract}
This study examined the knowledge and practice of daily exercises for the prevention and control of heart diseases among nurses in Nnewi, Anambra State, Nigeria. Three research questions guided the study. Related literatures were reviewed. By purpose based classification scheme, descriptive survey research design was used. The study population consisted ofone hundred and forty three nurses met on duty in different wards during the period of data collection. The instrument used for data collection was self-developed, structured, validated and reliable questionnaire which was administered on a face-to-face basis to the respondents. Data collected were analyzed using tables and percentages. The result revealed that the nurses have basic knowledge of the different types of exercises that will assist in the prevention of heart diseases but levels of implementation of exercises among the nurses as a measure to prevent heart diseases differs. It was recommended that persons of all ages should include physical activity in a comprehensive programme of health promotion and disease prevention and should increase their habitual physical activity to a level appropriate to their capacities, needs and interest.
\end{abstract}

\section{Background of the Study}

\section{Introduction}

Physical inactivity is recognized as a risk factor for coronary artery disease, a form of heart condition that involve narrowed or blocked blood vessels that can lead to a heart attack, chest pain (angina) or stroke. Other heart conditions such as infections and conditions that affect the hearts muscle, valves or beating rhythm are also considered forms of heart disease. Many forms of heart disease can be prevented or treated with healthy lifestyle choices like avoidance of smoking, eating a balanced meal and engaging in exercises daily (Brown, Burton \& Rowan 2007). Regular aerobic physical activity increases exercise capacity and plays a role in both primary and secondary prevention of heart diseases (Brown \& Rhodes 2009). Exercise training increases cardiovascular functioning capacity and decreases myocardial oxygen demand at any level of physical activity in apparently healthy persons and in most individuals with heart diseases.

Regular physical activity is required to maintain these training effects (Kruk, 2010).Exercise helps to improve and maintain the healthy state of the heart, and can even reverse some heart disease risk factors. Like all muscles, the heart becomes stronger as a result of exercise, so it can pump more blood through the body with every beat and continue working at maximum level, if needed, with less strain. The resting heart rate of those who exercise is also slower because less effort is needed to pump blood.According to Guytonand Hall (2006), three major effects that occur during exercise which are essential for the circulatory system to supply the tremendous blood flow required by the muscles include the mass discharge of the sympathetic nervous system throughout the body with consequent stimulatory effects on the entire circulation, increase in arterial pressure and increase in cardiac output.

Implementation of physical activity as strategies for both primary and secondary prevention should consider the dosing effect or expenditure of kilocalories or kilojoules over a unit of time (usually a week). The guidelines should entail 5-6 hours of various physical activities weekly if possible. The exercise routine must be individualized (exercise prescription) and should include both aerobic and resistance activities. The benefits of exercise are enhanced with good to excellent compliance with exercise and appropriate lifestyle modifications. Results of pooled studies (Gaziano, Manson \& Ridker 2007; Abbott, White\&Ross 2004) revealed that persons who modify their behaviour after myocardial infarction to include regular exercise have improved rates of survival. Recent studies have revealed that intensive multiple interventions such as smoking cessation, blood lipid reduction, weight control, and physical activity significantly decreased the rate of progression and, in some cases, led to regression in the severity of atherosclerotic lesions in persons with coronary disease (Mustelin, Silventoinen, PietilAinen, Rissanen \& Kaprio, 2009; Taylor, Ussher \& Faulkner, 2007). In addition, limited data 
indicate that higher-intensity exercise compared with lower-intensity exercise improves left ventricular ejection fraction in persons with coronary artery disease. Current activity status (i.e. persons remaining physically active or having been sedentary and becoming physically active) revealed the greatest decline in coronary artery disease risk.

Healthy persons as well as many persons with cardiovascular disease, including those with heart failure can improve exercise performance with training. This improvement is the result of increased ability to use oxygen to derive energy for work. Exercise training increases maximum ventilatory oxygen uptake by increasing both maximum cardiac output (the volume of blood ejected by the heart per minute, which determines the amount of blood delivered to the exercising muscles) and the ability of muscles to extract and use oxygen from blood. Elderly adults who exercise twice a week can significantly increase their body strength, flexibility, balance, and agility.

It has been observed that most nurses suffer from high blood pressure and some do not practice daily exercises, and some nurses in particular seems to be overweight. This made the researchers to assess the knowledge and practice of daily exercises in the prevention and control of heart diseases among nurses in Nnewi Anambra state.It is hoped that the outcome of the study will provide relevant information about some of the benefits of daily exercises on the cardiovascular system.

\section{Objectives of the Study}

1. To determine the awareness of nurses on the use of exercises to prevent heart diseases.

2. To find out the level of implementation of exercises among nurses as a measure to prevent heart diseases.

3. To determine the hindrances to the implementation of exercises as a means of preventing heart diseases.

\section{Research Questions}

1. Are nursesaware of the use of exercises to prevent heart diseases?

2. What is the level of implementation of exercises among the nurses as a measure to prevent heart diseases?

3. Are there hindrances for the implementation of exercise as a means of preventing heart diseases?

\section{Method and Materials}

This was a descriptive survey research to determine the knowledge and practice of daily exercises in the prevention and control of heart diseases among nurses in Nnewi.The population of the study consists of nurses working at different units in a hospital. The targeted population was about 255 which are distributed according to their units. The researchers used convenience sampling that included all the nurses available and willing to participate in the research at the time of data collection. Approval was obtained from the hospital research ethical committee. The objectives of the study were explained to participants and confidentiality was assured and informed consent received from them before they were included in the study. A pre-tested selfdeveloped questionnaire were utilized to elicit responses from the respondents. The data collected were organized and analyzed using frequencies and percentages for the research questions.

\section{Researcher question 1}

\section{Results and Observations}

Are the nurses aware of the use of exercises to prevent heart diseases?

Table 1: Respondent's awareness of the use of exercises to prevent heart diseases.

\begin{tabular}{|l|l|l|l|}
\hline & Response & Frequency & Percentage \\
\hline $\begin{array}{l}\text { Aware of use of exercises to prevent heart } \\
\text { diseases }\end{array}$ & Yes & 143 & 100 \\
\hline & No & 0 & 0 \\
\hline & Total & $\mathbf{1 4 3}$ & $\mathbf{1 0 0 \%}$ \\
\hline
\end{tabular}

Table 2:

\begin{tabular}{|l|l|l|l|}
\hline & Response & Frequency & Percentage \\
\hline Engage in exercises & Yes & 143 & 100 \\
\hline & No & 0 & 0 \\
\hline & Total & $\mathbf{1 4 3}$ & $\mathbf{1 0 0 \%}$ \\
\hline
\end{tabular}

The findings in tables 1 and 2 indicated that all the respondents (100\%) are awareof the use of exercises to prevent heart diseases and they all indicated to have engaged in various forms of exercises. The implication is that nurses have the basic knowledge of the prevention of heart diseases. 


\section{Researcher question 2}

What is the level of implementation of exercises among the nurses as a measures to prevent heart diseases?

Table 3: Types of Exercises Engaged in.

\begin{tabular}{|l|l|l|}
\hline Response & Frequency & Percentage \\
\hline Running & 95 & 66.4 \\
\hline Skipping & 21 & 14.7 \\
\hline Jogging & 5 & 3.50 \\
\hline Swimming & 1 & 0.70 \\
\hline Walking & 21 & 14.7 \\
\hline Total & $\mathbf{1 4 3}$ & $\mathbf{1 0 0 \%}$ \\
\hline
\end{tabular}

Table 4: Frequency of engaging in Different Exercises

\begin{tabular}{|l|l|l|}
\hline Response & Frequency & Percentage \\
\hline Daily & 9 & 6.3 \\
\hline Weekly & 49 & 34.3 \\
\hline Not frequently & 80 & 55.9 \\
\hline Monthly & 5 & 3.5 \\
\hline Total & $\mathbf{1 4 3}$ & $\mathbf{1 0 0}$ \\
\hline
\end{tabular}

The finding in tables 3 and 4 showed that all the respondents (100\%) indicated that they have fully participated in different types of exercises.66.4\% of respondent engage in running as a form of exercises, $21 \%$ skipping, $5 \%$ engage in jogging, $1 \%$ swimming while $21 \%$ of respondents engage in walking. Table 4 showed that $3.5 \%$ participated on monthly basis, $6.3 \%$ of the respondents participated in dailyexercises, $34.3 \%$ participated on weekly basis, and 55.9\% seldomly carry out the exercises.

\section{Researcher question 3:}

Are there hindrances to the implementation of exercises as a means of preventing heart diseases?

Table 5:

\begin{tabular}{|l|l|l|l|l|l|}
\hline $\mathbf{S} / \mathbf{N}$ & Hindrances & $\begin{array}{l}\text { Strongly } \\
\text { agree }\end{array}$ & Agree & Disagree & $\begin{array}{l}\text { Strongly } \\
\text { disagree }\end{array}$ \\
\hline 1 & $\begin{array}{l}\text { Shift duties done by nurses have contributed to lack of } \\
\text { performance of exercises. }\end{array}$ & $30.8 \%$ & $28.7 \%$ & $29.4 \%$ & $11.2 \%$ \\
\hline 2 & $\begin{array}{l}\text { Nurses do not engage in daily exercises after night } \\
\text { duties. }\end{array}$ & $17.5 \%$ & $17.5 \%$ & $32.2 \%$ & $32.9 \%$ \\
\hline 3 & $\begin{array}{l}\text { Individuals who have suffered cardiac arrest previously } \\
\text { do not engaging in exercises }\end{array}$ & $12.6 \%$ & $12.6 \%$ & $29.4 \%$ & $45.5 \%$ \\
\hline 4 & Old age affects performance of exercise & $7.8 \%$ & $9.5 \%$ & $4.5 \%$ & $78.8 \%$ \\
\hline 5 & Emotional fatigue affects performance of exercises. & $72 \%$ & $11.2 \%$ & $10.8 \%$ & $6 \%$ \\
\hline
\end{tabular}

From table 5 , it is indicated that $30.8 \%$ of the respondents strongly agreed that shift duties done by nurses have contributed to their lack of performance of exercises, $32.9 \%$ of the respondents strongly disagreed that nurses do not engage in daily exercises after night duties. $45.5 \%$ of the respondents strongly disagreed that individuals who have suffered cardiac arrest previously do not engage in exercises, $72 \%$ of respondents strongly agreed that emotional fatigue affects performance of exercises while $78.8 \%$ strongly disagreed that exercises should not be engaged in by older adults.

\section{Discussion of findings}

The result of the study showed that nurses have the basic knowledge and awareness of the use of exercise to prevent heart diseases as all the respondents (100\%) are aware and have participated in exercise both in the prevention and control of heart diseases. The result of the study also showed that while $66.4 \%$ of nurses engage in running as a form of exercise, $14.7 \%$ engage in skipping as a form of exercise and $3.5 \%$ jogging, $0.70 \%$ swimming while $14.7 \%$ engage in walking as a form of exercise. This implies that nurses have the basic knowledge of the different types of exercise that will assist in the prevention of heart diseases.

The result also showed that majority of the nurses believed that work related stress among nurses contributed to their not being involved in exercises. Others believed that exercises should not be practiced by older individuals andmany believed that individuals with heart diseases should not engage themselves in exercise. This shows that nurses believed that there are different hindrances to the implementation of exercise for the promotion of heart diseases and this have affected their levels of performance of physical exercises. 


\section{Implication of the Study}

Hindrance to the implementation of exercise mostly as indicated by nurses were job burnout and emotional stress after duty hours, making them unable to take up any routine exercises.Proper incentives and motivation should be given to the nurses as well as workshops on importance of exercises as a tool in promoting heart health and preventing diseases of the heart.

\section{Conclusion}

The study revealed that nurses in Nnewi have the basic knowledge and awareness of the use of exercises for the prevention of heart diseases and although quite a number of them practice exercises, most of them do not participate in exercises due to certain factors which hinder them from participating. They enumerated lack of time, work place stress and stressful nature of nursing profession as some of the hindrances. The researchers recommendedthat workshops and seminars should be organized to update nurses on their knowledge about exercises and formation of exercise groups which will serve as motivators for them to engage in regular physical activities.

\section{References}

[1]. Abbott R D White LR, \&Ross GW (2004).Walking and dementia in physically capable elderly men. JAMA. 292:1447-1453.

[2]. Brown WJ, Burton NW, Rowan PJ (2007).Updating the evidence on physical acting and health in women. American Journal of preventive Medicine. 33(5): 404-41.

[3]. Brown SG, Rhodes RE (2009).Relationship among dog ownership and leisure-time walking in western Canadian adults. American Journal of preventive Medicine, Feb; 30(2):131-6.

[4]. Byberg L, Melhus H, Gedeborg R (2009). Total mortality afterchanges in leisure time physical activity in 50 years old men: $35 y$ years follow-up of population based cohort Brit Med J; 338: b 688 .

[5]. Calton BA, Lacey JV.JR, Schatzkin A, Scharirer C, ColbertLH,Albanes D, Leitzmann, M. F. (2006). Physical activity and the risk of colon cancer among women: a prospective cohortstudy (untied state). Int J cancer Feb 17.

[6]. Gaziano JM, Manson JE, Ridker PM (2007). Primary and Secondary prevention of coronary heart diseases. In Libby: Braunwalds heart diseases: A Textbook of cardiovascular Medicine, $8^{\text {th }}$ ed Philadelphia, PA: Saunders; chap 45.

[7]. Kruk J., (2010). Lifetime physical activity and the risk of breastcancer: a case-control study cancer Detect prev. 31 (1): 18-28

[8]. Larson EB, Wang L, Bowen JD (2006). Exercises is associated with reduced risk for incident dementia among persons 65 years of age and older. Ann intern med. Jan 17; 144 (2): 73-81

[9]. Mustelin L, Silventoinen K, PietilAinen K, Rissanen A, Kaprio J(2009).Physical activity reduces the influence of genetic effects on BMI and waist circumference: a study in youngadult twins. Int J obes (lond). 33(1): 29-36.

[10]. Taylor A.H, Ussher M, Faulkner G (2007). The acute effects of exercises on cigarette cravings, Withdrawal symptoms, affect and smoking behavior: a systematic review, Addition.

[11]. 102:534-543.

[12]. Tehard B, Friedenveich CM, Oppert JM (2006). Effect of physical Activity on women at increased risk of breast cancer: result from the E3N cohort study. Cancer Epidemiol biomarkers Prev. Jan; 15 (1): 57-64. 